\title{
A Survey on the Knowledge and Performance of Obstetrics and Gynecology Specialists and Residents Regarding the Effect of Periodontal Diseases on Pregnancy Complications and Therapeutic Centers of Tehran University of Medical Sciences
}

\author{
Nima Nadafpour ${ }^{1}$, FB Ghaedi ${ }^{2}$, Zeinab Verdipanah ${ }^{3}$, Zahra Alizadeh tabari ${ }^{2}$ \\ 1. Assistant professor, periodontics Dept, Faculty of Dentistry, Tehran Medical Sciences, Islamic Azad University, Tehran, Iran \\ 2. Periodontics
}

3.Dentist

\begin{tabular}{l}
\hline ARTICLE INFO \\
\hline Article Type \\
Original Article \\
\hline Article History \\
Received: Sep 2018 \\
Accepted: Oct 2018 \\
ePublished: Nov 2018
\end{tabular}

\section{Keywords:}

Work Performance,

Knowledge, Periodontal

Diseases, Obstetric

Deliveries, Gynecology,

Pregnancy Complications

\begin{abstract}
Background and Aim: The knowledge and performance of obstetrics and gynecology (OBG) specialists regarding the relationship between maternal periodontal disease and pregnancy complications are unclear, especially in Iran. Considering the key role of this group in evaluating pregnant women at risk, we aimed to determine the knowledge and performance of OBG specialists and residents regarding the effects of periodontal disease on pregnancy outcomes at therapeutic centers of Tehran University of Medical Sciences.

Materials and methods: Questionnaires containing individual and exclusive questions were provided to OBG specialists and residents. Of the 92 questionnaires, 67 were returned, of which 58 were evaluable. Absolute and relative frequencies and the knowledge and performance scores of each group were determined and compared. Data were analyzed using independent t-test and Chi-square test.

Results: $71 \%$ of OBG residents and $77.8 \%$ of OBG specialists were familiar with periodontal disease via scientific texts. The mean awareness score of OBG residents and specialists was respectively $69.13 \pm 15.35$ and $83.7 \pm 16.7$; the difference was significant. There was no significant correlation between the awareness of gynecologists about the effect of periodontal diseases on pregnancy outcomes with their work experience. The mean performance scores of OBG specialists and residents was $51.13 \pm 31.1$ and $41.9 \pm 28.8$, respectively, with no significant difference. There was no significant relationship between the referral behaviors of OBG specialists and their work experience.

Conclusion: The awareness of OBG specialists and residents about the correlation between pregnancy and gingival disease was good, but their performance was moderate. Attendance of OBG specialists and residents to retraining courses will improve their awareness and performance.
\end{abstract}

Please cite this paper as: Nadafpour N,Ghaedi FB, Verdipanah Z, Alizadeh tabari Z. A Survey on the Knowledge and Performance of Obstetrics and Gynecology Specialists and Residents Regarding the Effect of Periodontal Diseases on Pregnancy Complications and Therapeutic Centers of Tehran University of Medical Sciences. J Res Dentomaxillofac Sci. 2018; 3 (4):33-40 


\section{Introduction:}

Nowadays, $11 \%$ of the births around the world are preterm, and despite the improvement in medical care, this rate appears to be rising in western countries. Such infants have a high risk of developing other acute and chronic conditions, such as respiratory distress syndrome, cerebral palsy, heart disease, and learning difficulties. ${ }^{(1)}$

Several risk factors have been identified for preterm birth and other adverse pregnancy outcomes, including maternal age, tobacco use, race, and recently, periodontitis. In 1931, Galloway first introduced periodontal disease as an infectious disease that could have harmful effects on the fetus. ${ }^{(2)}$ Although the importance of these effects was not considered for many years, today, the increasing volume of epidemiological studies report the negative association of periodontitis with adverse pregnancy outcomes ${ }^{(3-5)}$ although the exact mechanism by which periodontal disease can affect preterm birth is not yet clear. ${ }^{(6)}$

Preterm birth and low birth weight (PLBW) are among the most common causes of neonatal death and are the major cause of long-term disability among the newborns. ${ }^{(7,8)}$ Overall, 16\% (more than 200 million) of infants are born with low birth weight. Approximately, 25\% of low birth weight and preterm cases are without any underlying risk factor, whereas $18.2 \%$ of the cases can be related to periodontal disease. ${ }^{(7)}$

Periodontal disease is the most common chronic disease in the world, ${ }^{(8)}$ and the high relative incidence (about 20\%) of this disease among pregnant women in different countries indicates the need to identify and treat it in the population at risk. Health care during pregnancy is effective in decreasing the birth of low weight infants, and economically, every dollar spent on pregnancy care leads to economic saving of 2.57 dollars. ${ }^{(9)}$ In the United States, $74 \%$ of pregnant women do not receive pregnancy care. ${ }^{(10)}$ In France, 56\% of pregnant women do not meet a dentist during pregnancy. ${ }^{(11)}$

The percentage of obstetrics and gynecology (OBG) specialists who are aware of the relationship between pregnancy outcomes and periodontal disease varies from $84 \%$ in North America to
$64 \%$ in India, ${ }^{(12-15)}$ and more interestingly, despite the acceptable level of knowledge about the effects of oral health and periodontal disease on pregnancy, it does not seem that this awareness influences the referral behavior of the specialists as expected. ${ }^{(16,17)}$

Nevertheless, there is very little information about the knowledge of OBG specialists about periodontal disease and its effects on pregnancy in Iran, while it seems that proper knowledge and adequate performance in this field can reduce the adverse complications of pregnancy with consequent positive effects on the health and economy of the community.

Therefore, the aim of this study was to determine the level of knowledge and performance of OBG specialists and residents regarding the effect of periodontal diseases on pregnancy outcomes in pregnant women at therapeutic centers of Tehran University of Medical Sciences.

\section{Materials and Methods:}

This descriptive-analytical, cross-sectional study was conducted at educational and therapeutic centers of Tehran University of Medical Sciences. Data were collected using a self-administered questionnaire. The questionnaire was anonymous and its completion was optional. The study population included all OBG specialists and residents of the last two years of this major who completed at least half of their education and were engaged in therapeutic activities at educational and therapeutic centers of Teheran University of Medical Sciences.

In order to collect the necessary information, a questionnaire, consisting of 19 questions and three sections of individual questions, awarenessrelated questions, and performance-related questions, was designed. To assess the validity of the questionnaire, it was presented to the faculty members of the related department at the school of dentistry, and their views were applied to the questionnaire. In order to assess the reliability of the questionnaire, 15 OBG specialists and residents were randomly selected and completed the questionnaire. The questionnaire was completed by the same people two weeks later. Cronbach's alpha method was used to estimate the reliabil- 
ity of the questionnaire. Cronbach's alpha was 1.74 , which indicates an acceptable level of reliability. Then, the questionnaire was distributed by departmental staff among OBG specialists and residents during job shifts. Individual questions included age, the field of activity, work experience, and educational degree. In the exclusive questions section, awareness was evaluated using questions about the diagnosis and importance of periodontal disease, and performance was assessed through designing questions focusing on the referral of patients for dental visits and awareness of the necessary measures for timely prevention and treatment of dental diseases during pregnancy. The questionnaires were finally collected after a week, and completed questionnaires were analyzed using SPSS 19 software (SPSS Inc., Chicago, IL, USA). The absolute (number) and relative (percentage) frequencies were determined and reported. In the ranking of the results of each field, first, the score of each field was obtained according to the correct answers, then, all the scores were reached to 100 , and finally, scores of 0-33 were considered weak, scores of 33-66 were considered moderate, and scores higher than 66 were considered good. Independent t-test was applied to determine the significant difference between the mean knowledge and performance of OBG specialists and residents, and Chi-square test was used to determine the relationship between the knowledge and performance of gynecologists and their work experience.

\section{Results:}

In this research, 67 OBG specialists and residents completed the research questionnaire. Nine questionnaires were excluded from the study due to incomplete data, and 58 questionnaires were analyzed. Of these, 31 cases (53.4\%) were related to OBG residents, and 27 cases (46.6\%) were related to OBG specialists.

The mean number of preterm or low birth weight deliveries was $10.17 \pm 9.8$ per month in the report of OBG residents and 5.7 \pm 4.9 per month in the report of OBG specialists.

On average, the number of monthly deliveries was $45.4 \pm 69.5$ in the report of OBG residents and $20.3 \pm 14.8$ in the report of OBG specialists.

$70.4 \%$ of OBG specialists had a work history of more than 10 years, $11.1 \%$ had a work history of 5 to 10 years, and $18.5 \%$ had a work history of below 5 years.

$71 \%$ of OBG residents and $77.8 \%$ of OBG specialists were familiar with periodontal disease.

Scientific texts, with the frequency of $54.5 \%$, had the major role in the familiarity of OBG residents with periodontal diseases, whereas the dentists, with the frequency of $36.4 \%$, were in the next rank. In the familiarity of OBG specialists with periodontal diseases, scientific texts and academic education, each with the frequency of $38.1 \%$, had the major role (Table 1).

Table 1: Frequency distribution of the manner of familiarity with periodontal disease in the studied obstetrics and gynecology (OBG) residents and specialists.

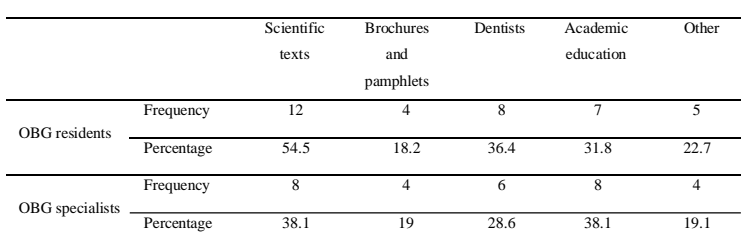

$O B G=$ Obstetrics and Gynecology

Only $16.1 \%$ of OBG residents and $11.3 \%$ of OBG specialists participated in retraining courses related to oral and dental diseases and pregnancy.

In the evaluation of the awareness questions, $90.3 \%$ of the residents and $96.3 \%$ of the specialists were aware of the increased incidence of gingival disease symptoms in pregnancy.

$90.3 \%$ of the residents and $100 \%$ of the specialists were aware of the relationship between periodontal disease and adverse pregnancy outcomes, such as preterm births or low birth weight. $80.6 \%$ of the residents and $96.3 \%$ of the specialists considered periodontal treatments safe during pregnancy.

$54.8 \%$ of the residents considered caries as the main cause of periodontal disease and $22.6 \%$ considered bacteria as the main cause of this disease, while regarding the specialists, this rate was $18.5 \%$ and $59.3 \%$, respectively (Table 2 ). 
Table 2: Frequency distribution of the response to the question "What is the main cause of periodontal disease?"

\begin{tabular}{llcccccc}
\hline & & $\begin{array}{c}\text { Dental } \\
\text { caries }\end{array}$ & Ageing & Bacteria & $\begin{array}{c}\text { Sugar } \\
\text { overuse }\end{array}$ & $\begin{array}{c}\text { Ido } \\
\text { not } \\
\text { know }\end{array}$ & Total \\
\hline $\begin{array}{l}\text { OBG } \\
\text { residents }\end{array}$ & Frequency & 17 & 1 & 7 & 2 & 4 & 31 \\
\cline { 2 - 8 } & Percentage & 54.8 & 3.2 & 22.6 & 6.5 & 12.9 & 100 \\
\hline $\begin{array}{l}\text { OBG } \\
\text { specialists }\end{array}$ & Frequency & 5 & 1 & 16 & 1 & 4 & 27 \\
\cline { 2 - 8 } & Percentage & 18.5 & 3.7 & 59.3 & 3.7 & 14.8 & 100 \\
\hline
\end{tabular}

\section{OBG=Obstetrics and Gynecology}

$58.1 \%$ of the residents and $70.4 \%$ of the specialists considered the second trimester of pregnancy as the best time for periodontal treatment.

The mean score of the knowledge of OBG residents was $69.03 \pm 15.35 \%$, and the mean knowledge score of the specialists was $83.7 \pm 16.7 \%$, both of which were in good range. The mean scores of the knowledge of OBG residents and specialists were significantly different $(\mathrm{P}<0.05)$.

The knowledge of $81.5 \%$ of the specialists and $51.6 \%$ of the residents was estimated to be good. Although the highest frequency of good knowledge status was observed in specialists with more than 10 years of work experience, there was no significant relationship between the work experience and the state of knowledge $(\mathrm{P}=0.43$ and $\mathrm{X} 2=1.65)$.
$58.1 \%$ of the residents and $51.9 \%$ of the specialists always assessed the oral health history of their patients.

$35.5 \%$ of the residents and $22.2 \%$ of the specialists gave awareness to all their patients regarding the relationship between gingival disease and pregnancy complications.

$51.6 \%$ of the residents and $37 \%$ of the specialists always referred their patients for oral examinations.

Rinsing with salt water was the most commonly prescribed method by OBG residents and specialists as a medication before referring to a dentist (Table 3).

Table 3: Frequency distribution of the answer to the question "What drug do you prescribe if a pregnant patient with a gingival problem (bleeding, swelling, etc.) insists on prescribing a medication before referring to a dentist?"

\begin{tabular}{|c|c|c|c|c|c|c|c|c|}
\hline & & $\begin{array}{c}\text { No } \\
\text { medicatio } \\
n, \\
\text { except for } \\
\text { salt water }\end{array}$ & $\begin{array}{l}\text { Antiseptic } \\
\text { mouthwash }\end{array}$ & Antibiotics & Analgesics & $\begin{array}{c}\text { Anti- } \\
\text { inflammatory } \\
\text { drugs }\end{array}$ & $\begin{array}{l}\text { Vitamin C } \\
\text { supplement }\end{array}$ & Total \\
\hline \multirow{2}{*}{ OBG residents } & Frequency & 18 & 6 & 4 & 1 & 1 & 1 & 31 \\
\hline & Percentage & 58.1 & 19.4 & 12.9 & 3.2 & 3.2 & 3.2 & 100 \\
\hline \multirow{2}{*}{$\begin{array}{l}\text { OBG } \\
\text { specialists }\end{array}$} & Frequency & 13 & 4 & 4 & 2 & 2 & 2 & 27 \\
\hline & Percentage & 48.1 & 14.8 & 14.8 & 7.4 & 7.4 & 7.4 & 100 \\
\hline
\end{tabular}

$O B G=$ Obstetrics and Gynecology 
$71 \%$ of the residents and $66.7 \%$ of the specialists did not include a question regarding the health of the gingivae and the periodontium in the medical records of their pregnant patients. The average performance score was $50.03 \pm 30.1 \%$ for the residents and $41.9 \pm 28.8 \%$ for the specialists; both scores were moderate (Table 4). There was no significant difference in the performance scores of the aforementioned two groups $(\mathrm{P}>0.05)$.

Table 4: Estimation of dispersion parameters and average performance scores of obstetrics and gynecology (OBG) residents and specialists regarding periodontal diseases

\begin{tabular}{lccccccc}
\hline \multicolumn{1}{c}{ Performance } & Range & Minimum & Maximum & Mean & SD & Status & P-value \\
\hline OBG residents & 80 & 20 & 100 & 50.03 & 30.1 & Moderate & 0.453 \\
& & & & & & & \\
\hline OBG specialists & 90 & 10 & 100 & 41.9 & 28.8 & Moderate \\
& & & & & & & \\
\hline
\end{tabular}

$\mathrm{SD}=$ Standard Deviation

The performance of $37.7 \%$ of the residents and $55.6 \%$ of the specialists was in poor range.

The most frequent $(40.7 \%)$ poor performance was observed in specialists with a history of more than 10 years of work experience. However, the relationship between these two variables was not significant $(\mathrm{P}=0.24$ and $\mathrm{X} 2=5.4)$.

\section{Discussion:}

Currently, preterm birth is the second most common cause of death in children under the age of 5 years. ${ }^{(18)}$ Pregnancy complications, including PLBW, are associated with an increase in local and systemic inflammatory mediators and intrauterine infections. Maternal periodontitis is a source of entry of microorganisms into the bloodstream that can directly or indirectly affect the health of the fetus. $^{(19)}$

Several studies have shown the effects of maternal periodontal disease on preterm birth and low birth weight of infants. ${ }^{(20-25)}$

Studies estimate that $18.2 \%$ of all PLBWs can be caused by maternal periodontal disease. ${ }^{(26)}$ In their systematic review in 2012, Shanthi et al introduced periodontal disease as a risk factor associated with PLBWs. ${ }^{(27)}$ However, the American Academy of Periodontology and the European Society of Periodontology stated in their latest report that the strength of the association between mater- nal periodontitis and PLBW is moderate and may vary based on the population studied, the manner of assessment of the periodontal status, and the classification used in periodontal disease assessment. ${ }^{(18)}$

Overall and according to studies conducted, doctors generally do not examine their patients' mouths, mostly because of the lack of training in this area. ${ }^{(28,29)}$ In 2000 , Lewis et al showed that half of the doctors in their study did not receive instruction regarding oral examinations during the course of medical education or residency. ${ }^{(28)}$

The present study showed that a high percentage of OBG residents and specialists ( $71 \%$ and $77.8 \%$, respectively) were familiar with periodontal disease, and the awareness of both groups about the relationship between periodontal disease and pregnancy complications was good.

$100 \%$ of the specialists and $90.3 \%$ of the residents were aware of the possibility of a relationship between periodontal disease and pregnancy complications, and $96.3 \%$ of the specialists and $90.3 \%$ of the residents were aware that pregnancy can cause or aggravate gingival disease symptoms in pregnant women. These results were better than the results reported by Nutalapati et al, ${ }^{(26)}$ Tarannum et 
al, ${ }^{(14)}$, and Shenoy and colleagues ${ }^{(30)}$ in India, as well as the results of a study by Patil and colleagues ${ }^{(31)}$ in Saudi Arabia; this can be explained considering the study population in the present research, who worked in the educational section. This has been confirmed in studies by Patil et al ${ }^{(31)}$ and Shenoy et al ${ }^{(30)}$ as well.

The awareness results were similar to the findings of a study by Strafford et al ${ }^{(32)}$ in the United States on a mixed population including all pregnant women's caregivers including nurses, doctors, midwives, and specialists, and similar to those of studies by Wilder et al ${ }^{(12)}$ in North Carolina, Cohen et al ${ }^{(33)}$ in France, and Rocha et al ${ }^{(34)}$ in Brazil.

In comparing the level of awareness among the group of residents and specialists, the level of knowledge of OBG specialists was significantly higher, which is justified by the higher level of literacy among these specialists.

Performance evaluation showed moderate results in both groups. $56 \%$ of the residents and $37 \%$ of the specialists always referred their patients for oral examinations. The performance score of the residents was higher than that of the specialists, although the difference was not statistically significant. This suggests that a higher knowledge level of the specialists does not necessarily lead to better performance.

Similar to the results obtained for awareness, in terms of the performance, the present study showed better results than studies by Nutalapati et al ${ }^{(26)}$ and Patil et al ${ }^{(31)}$, and the results were close and comparable with those of studies by Wilder et al, ${ }^{(12)}$ Cohen et al, ${ }^{(33)}$ and Strafford et al. ${ }^{(32)}$

Although the referral rate in the present study was acceptable and comparable with similar studies, $71 \%$ of the residents and $66.7 \%$ of the specialists did not include a question about periodontal health assessment in their patients' medical records, which is a point to be considered and reviewed.

Similar to other studies, such as those con- ducted by Cohen et al ${ }^{(33)}$, Rocha et al ${ }^{(34)}$, and Zanata et al, ${ }^{(15)}$ performance was at a weaker level than awareness.

What is to be considered in this regard is that although the knowledge of the specialists and the residents of this study was well maintained and even improved with increasing the years of experience, performance was moderate and even declined further with increasing the years of experience. This indicates that the acquired knowledge is not internalized and, therefore, it cannot be practiced and is diminished over time.

In the study of the manner of the familiarity of OBG specialists and residents with periodontal disease, the main role was played by primary academic education and dentists. $83 \%$ of the residents and $88 \%$ of the specialists did not participate in retraining courses on the correlation between oral and dental diseases and pregnancy, which could be one of the reasons for the inadmissibility of awareness in this regard and their weak performance.

\section{Conclusion:}

Overall, the awareness of OBG residents and specialists about the relationship between pregnancy and the probability of gingival disease was good, while the performance status was weaker and moderate. Considering this issue and the fact that the source of the knowledge of OBG specialists and residents is merely academic and dental training, it seems necessary to provide regular retraining courses in order to review and update the knowledge and to internalize its value for use in the clinic. The absence of a course in the field of oral and dental health in the educational curriculum of this group reveals the need for planning the provision of oral and dental sciences to the target group.

\section{Acknowledgements:}

We thank the employees of the obstetrics and gynecology wards of the hospitals affiliated to Tehran University of Medical Sciences, who collaborated with the researchers in col- 
lecting data for this study. This article is derived from the Thesis No. 622 registered at the School of Dentistry of Qazvin University of Medical Sciences, entitled the evaluation of knowledge and performance of obstetrics and gynecology specialists and residents regarding the effects of periodontal diseases on pregnancy complications at educational and therapeutic centers of Tehran University of Medical Sciences.

\section{References:}

1. Zahed Pasha Y, Esmaeili Dooki M, Haji Ahmadi M, Asgardon G, Ghadimi R, Baleghi M, et al. Effect of Risk Factors on Low Birth Weight Neonates. JBUMS. 2004;6(2):18-24. 2. Michalowicz BS, Gustafsson A Thumbigere-Math V, Buhlin $\mathrm{K}$. The effects of periodontal treatment on pregnancy outcomes. J Periodontol. 2013 Apr;84(4 Suppl):S195-208.

3. Rajapakse PS, Nagarathne M, Chandrasekra KB, Dasanayake AP. Periodontal disease and prematurity among non-smoking Sri Lankan women. J Dent Res. 2005 Mar;84(3):274-7.

4. Agueda A, Ramón JM, Manau C, Guerrero A, Echeverría JJ. Periodontal disease as a risk factor for adverse pregnancy outcomes: a prospective cohort study. J Clin Periodontol. 2008 Jan;35(1):16-22.

5. Gomes-Filho IS, Cruz SS, Rezende EJ, Dos Santos CA, Soledade KR, Magalhães MA, et al. Exposure measurement in the association between periodontal disease and prematurity/low birth weight. J Clin Periodontol. 2007 Nov;34(11):957-63.

6. Baccaglini L. A meta-analysis of randomized controlled trials shows no evidence that periodontal treatment during pregnancy prevents adverse pregnancy outcomes. J Am Dent Assoc. 2011 Oct;142(10):1192-3.

7. Al-Habashneh R, Aljundi SH, Alwaeli HA. Survey of medical doctors' attitudes and knowledge of the association between oral health and pregnancy outcomes. Int J Dent Hyg. 2008 Aug;6(3):214-20.
8. Chang HH1, Larson J, Blencowe H, Spong CY, Howson CP, Cairns-Smith S, et al.

Preventing preterm births: analysis of trends and potential reductions with interventions in 39 countries with very high human development index.Lancet. 2013 Jan 19;381(9862):223-34.

9. Emrich LJ, Shlossman M, Genco RJ. Periodontal disease in non-insulin-dependent diabetes mellitus. J Periodontol. 1991 Feb;62(2):123-31.

10. Boggess KA, Urlaub DM, Massey KE, Moos MK, Matheson MB, Lorenz C. Oral hygiene practices and dental service utilization among pregnant women. J Am Dent Assoc. 2010 May;141(5):553-61.

11. Vergnes JN, Pastor-Harper D, Constantin D, Bedos C, Kaminski M, Nabet C, et al. [Perceived oral health and use of dental services during pregnancy: the MaterniDent study]. [Article in French]. Sante Publique. 2013 May-Jun;25(3):281-92.

12. Wilder R, Robinson C, Jared HL, Lieff S, Boggess K. Obstetricians' knowledge and practice behaviors concerning periodontal health and preterm delivery and low birth weight. J Dent Hyg. 2007 Fall;81(4):81.

13. Morgan MA, Crall J, Goldenberg RL, Schulkin J. Oral health during pregnancy. J Matern Fetal Neonatal Med. 2009 Sep;22(9):733-9.

14. Tarannum F, Prasad S; Muzammil, Vivekananda L, Jayanthi D, Faizuddin M. Awareness of the association between periodontal disease and pre-term births among general dentists, general medical practitioners and gynecologists. Indian J Public Health. 2013 Apr-Jun;57(2):92-5.

15. Zanata RL, Fernandes KB, Navarro PS. Prenatal dental care: evaluation of professional knowledge of obstetricians and dentists in the cities of Londrina/PR and Bauru/ SP, Brazil, 2004. J Appl Oral Sci. 2008 MayJun;16(3):194-200.

16. Ishikawa I, Sasaki KM, Aoki A, Watanabe H. Effects of Er:YAG laser on peri- 
odontal therapy. J Int Acad Periodontol. 2003 Jan;5(1):23-8.

17. Offenbacher S. Periodontal diseases: pathogenesis. Ann Periodontol. 1996 Nov;1(1):821-78.

18. Sanz M, Kornman K; working group 3 of the joint EFP/AAP workshop. Periodontitis and adverse pregnancy outcomes: consensus report of the Joint EFP/AAP Workshop on Periodontitis and Systemic Disease. J Periodontol. 2013 Apr;84(4 Suppl):S164-9.

19. Oppermann RV, Weidlich P, Musskopf ML. Periodontal disease and systemic complications. Braz Oral Res. 2012;26 Suppl 1:39-47.

20. Jeffcoat MK, Geurs NC, Reddy MS, Cliver SP, Goldenberg RL, Hauth JC. Periodontal infection and preterm birth: results of a prospective study. J Am Dent Assoc. 2001 Jul;132(7):875-80.

21. López NJ, Smith PC, Gutierrez J. Higher risk of preterm birth and low birth weight in women with periodontal disease. J Dent Res. 2002 Jan;81(1):58-63.

22. Offenbacher S, Lieff S, Boggess KA, Murtha AP, Madianos PN, Champagne CM, et al. Maternal periodontitis and prematurity. Part 1: Obstetric outcome of prematurity and growth restriction. Ann Periodontol. 2001 Dec;6(1):164-74.

23. Moreu G, Téllez L, González-Jaranay M. Relationship between maternal periodontal disease and low-birth-weight pre-term infants. J Clin Periodontol. 2005 Jun;32(6):6227.

24. Jeffcoat MK, Geurs NC, Reddy MS, Goldenberg RL, Hauth JC. Current evidence regarding periodontal disease as a risk factor in preterm birth. Ann Periodontol. 2001 Dec;6(1):183-8.

25. Marin C, Segura-Egea JJ, Martínez-Sahuquillo A, Bullón P. Correlation between infant birth weight and mother's periodontal status. J Clin Periodontol. 2005 Mar;32(3):299-304. 26. Nutalapati R, Ramisetti A, Mutthineni RB, Jampani ND, Kasagani SK. Awareness of association between periodontitis and
PLBW among selected population of practicing gynecologists in Andhra Pradesh. Indian J Dent Res. 2011 Sep-Oct;22(5):735.

27. Shanthi V, Vanka A, Bhambal A, Saxena V, Saxena S, Kumar SS. Association of pregnant women periodontal status to preterm and low-birth weight babies: A systematic and evidence-based review. Dent Res J (Isfahan). 2012 Jul;9(4):368-80.

28. Lewis CW, Grossman DC, Domoto PK, Deyo RA. The role of the pediatrician in the oral health of children: A national survey. Pediatrics. 2000 Dec;106(6):E84.

29. Roberts MW, Keels MA, Sharp MC, Lewis JL Jr. Fluoride supplement prescribing and dental referral patterns among academic pediatricians. Pediatrics. 1998 Jan;101(1):E6.

30. Shenoy RP, Nayak DG, Sequeira PS. Periodontal disease as a risk factor in pre-term low birth weight--an assessment of gynecologists' knowledge: a pilot study. Indian J Dent Res 2009 Jan-Mar;20(1):13-6.

31. Patil SN, Kalburgi NB, Koregol AC, Warad SB, Patil S, Ugale MS. Female sex hormones and periodontal health-awareness among gynecologists - A questionnaire survey. Saudi Dent J. 2012 Apr;24(2):99-104.

32. Strafford KE, Shellhaas C, Hade EM. Provider and patient perceptions about dental care during pregnancy. J Matern Fetal Neonatal Med. 2008 Jan;21(1):63-71.

33. Cohen L, Schaeffer M, Davideau JL, Tenenbaum H, Huck O. Obstetric Knowledge, Attitude, and Behavior Concerning Periodontal Diseases and Treatment Needs in Pregnancy: Influencing Factors in France. J Periodontol. 2015 Mar;86(3):398-405.

34. Rocha JM, Chaves VR, Urbanetz AA, Baldissera Rdos S, Rösing CK. Obstetricians' knowledge of periodontal disease as a potential risk factor for preterm delivery and low birth weight. Braz Oral Res. 2011 May-Jun;25(3):248-54. 